\title{
The Rate Dependent Tensile Response of Polycarbonate and Poly-methylmethacrylate
}

\author{
Mark Foster ${ }^{1} \cdot$ Bryan Love $^{2} \cdot$ Robert Kaste $^{2} \cdot$ Paul Moy $^{2}$
}

Received: 9 March 2015/Accepted: 11 April 2015/Published online: 23 April 2015

(C) Society for Experimental Mechanics, Inc 2015

\begin{abstract}
The tensile mechanical response of polycarbonate and polymethyl-methacrylate is investigated across a range of strain rates from 0.001 to $1600 \mathrm{~s}^{-1}$. Traditional standard ASTM tensile experiments are limited to low strain rates and do not give quantitative data for plastic behavior for strain softening materials. In this study, a novel specimen and gripping geometry is designed and verified to mitigate wave reflections present in previous high strain rate tensile experiments. Digital image correlation is used to extract local deformation measurements, and a Kolsky bar technique typically used for fiber experiments is adapted for soft polymers. The insights gathered in this study will provide a further step toward a high fidelity material model for both ductile and brittle polymers.
\end{abstract}

Keywords Dynamic tension - Kolsky bar .

Polycarbonate · Polymethyl-methacrylate $\cdot$ Digital image correlation

The research reported in this document was performed in connection with contract/instrument W911QX-14-C-0016 with the U.S. Army Research Laboratory. The views and conclusions contained in this document are those of TKC Global and the U.S. Army Research Laboratory. Citation of manufacturer's or trade names does not constitute an official endorsement or approval of the use thereof. The U.S. Government is authorized to reproduce and distribute reprints for Government purposes notwithstanding any copyright notation hereon.

Mark Foster

mark.foster12.ctr@mail.mil

1 TKC Global Inc., 13873 Park Center Road, Suite 400 North, Herndon, VA 20171, USA

2 Army Research Laboratory, 4600 Deer Creek Loop, Aberdeen Proving Ground, MD 21005, USA

\section{Introduction}

Both polycarbonate (PC) and polymethyl-methacrylate (PMMA) are frequently used in safety guards and shields due to a combination of transparency and impact resistance. Both materials exhibit similar density, elastic modulus, yield strength, and glass transition temperature. However, PC typically exhibits on the order of $100 \%$ elongation before tensile failure, whereas PMMA fractures in a brittle manner at a few percent strain. This disparity in fracture behavior as well as the influence of temperature, pressure and strain rate on the mechanical response of these polymers is important in predicting their behavior during impact events. When a material undergoes a penetration event, a tensile mode frequently dominates the final failure mechanism on the back surface, thus controlling breakout and, ultimately, influencing limit velocities.

Test methods for the tensile properties of polymers have been largely underdeveloped beyond that of the ASTM D638 standard, and the interdependence of temperature, pressure, and strain rate is not yet well understood. The ASTM D638 standard test method for the tensile properties of plastics specifies a suitable specimen design and displacement rate for reliable data, but this method only applies to strain rates less than $0.25 \mathrm{~s}^{-1}$; much lower than strain rates applicable to impact or blast conditions [1]. Nor does the standard account for any nonuniform mechanical behavior beyond yield, where instead it calls for "nominal" values during necking that are of "qualitative utility only" [1]. High strain rate experiments require specimens of shorter gage lengths due to the limits on the displacement in the Kolsky bar. Chen, Lu and Cheng [2] developed a threaded specimen for loading of PMMA in tension at high strain rates. This threaded design was used by both $\mathrm{Fu}$ et al. [3] and Sarva et al. [4] for experiments on PC, and in a 
study by Rae and Brown [5] on polytetrafluoroethylene (PTFE) at high strain rates. Dwivedi et al. [6] also used a similar threaded design to examine the tensile response of PC, but only at low loading rates. Work performed by Cao [7] incorporated flat dogbone PC specimens, which required a high strength adhesive to bond the specimen to the grips. In this work, we explore the use of the threaded specimen proposed by Chen [2], and develop a new specimen and gripping method for Kolsky bar testing of polymers that overcomes some of the difficulties encountered with the threaded method.

Numerous constitutive models have been developed to capture the mechanical response of PMMA and PC. Bauwens [8], Bergstrom and Boyce [9], Mulliken and Boyce [10], Richeton et al. [11], and Safari et al. [12] have all developed continuum-level models for polymers, with various internal state variables to capture the viscoplastic evolution. Many of the proposed models are developed to cover a wide range of stress states and strain rates, but are primarily calibrated using the results of low and high strain rate compressive data. This study seeks to provide data for higher fidelity models by characterizing the tensile behavior of both PC and PMMA over a wide range of strain rates from 0.001 to $1500 \mathrm{~s}^{-1}$. Furthermore, we seek to utilize a simple model for PC to iteratively develop a new specimen type and, ultimately, gather constitutive behavior from Kolsky tension bar experiments.

Various techniques have been established to subject materials to high loading rates. Some of these techniques include flyer plate impact, Taylor impact, drop tower methods, and pressure shear experiments, but perhaps the most widely used would be the Kolsky bar or split Hopkinson pressure bar (SHPB). Since its original development by Kolsky [13] the method has seen much refinement; most developments for low impedance materials involve polymeric bars $[14,15]$ and associated dispersion corrections [16], wave separation [17, 18], pulse shaping [19, 20], long bar lengths [21], high sensitivity semiconductor strain gages, hollow transmission bars [22], or embedded quartz load cells [23]. Each evolution poses advantages and shortcomings and none have proven to be ideal for all materials or loading conditions. For example, hollow bars, polymeric bars, and long bar lengths provoke wave dispersion and semiconductor strain gages vary in linearity and sensitivity according to ambient conditions. Nonetheless, with these necessary developments, much attention has also been paid to a condition known as dynamic equilibrium; defined as a state where the forces on each end of the specimen are equivalent [24-26]. This is not always simple to verify in dynamic experiments, as these forces are usually measured indirectly, and while strain gages do resolve incident and reflected pulses, they may inaccurately describe what occurs in the specimen. Pulse shaping is another technique which is often used as a low-pass filter to dampen higher frequency oscillations and increase the rise time of the incident loading pulse. While a longer rise time increases the likelihood of dynamic equilibrium, it does not solely satisfy this condition, especially in cases with long specimen gage lengths.

We overcome these shortcomings in this study by using local measurements at the specimen. A Kolsky bar technique to evaluate tensile properties of single fibers was first described by Cheng [27] and later used by Lim [28] and Sanborn [29]. This procedure replaces the transmission bar with a dynamic load cell to directly measure the transmitted load at the specimen. In this study, their technique is combined with digital image correlation (DIC) to measure the load and strain directly at the specimen at high loading rates. A novel conical specimen configuration was employed to reduce wave reflections that occurred in threaded specimens at high strain rate, and results were compared to quasi-static ASTM D638 tests for verification.

\section{Material}

The materials utilized in this study were Lexan 9030 extruded sheet (PC) and cell-cast Plexiglass G sheet (PMMA). Both sheets were nominally $12.7 \mathrm{~mm}$ in thickness, allowing for a range of specimen designs. Specimens were cut in orthogonal directions along the sheets, and no anisotropy was seen in either material throughout our experiments. One sample set of PMMA specimens was annealed to ensure that machining did not introduce residual stresses that would affect mechanical response. The various specimen configurations utilized in testing are further detailed in Fig. 1.

The DIC strain measurement required the application of a high contrast speckle pattern to the front surface of the specimens. The ASTM specimens received a white basecoat and black speckle topcoat while the threaded specimens were speckled with ink and backlit to give a randomized high contrast pattern. Figure 2 shows typical examples of these surface patterns on the different specimen designs.

\section{Experiment}

\section{Low and Intermediate Strain Rates}

A servo-hydraulic load frame was used for the quasi-static and intermediate rate experiments on all specimen designs. A pair of Point Grey Research GRAS-50S5M-C cameras was used for the low rate experiments for a higher resolution image, while two Photron APX-RS cameras 
Fig. 1 Threaded and ASTM D638 Type III specimens used in this study
Fig. 2 DIC patterns of various resolutions
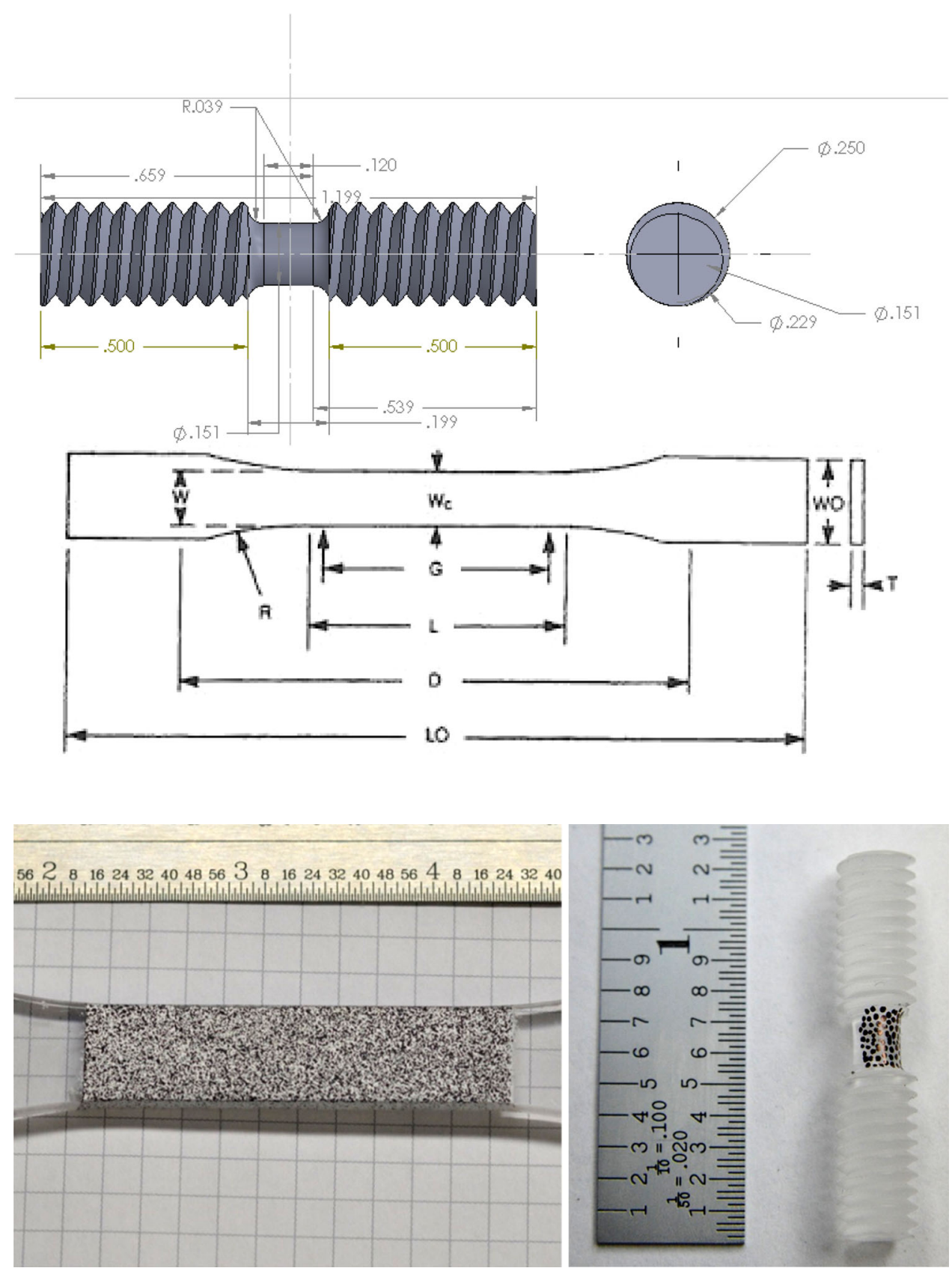

were used at $500 \mathrm{fps}$ for intermediate rates. Images from both low and intermediate rate tests were processed in Correlated Solutions Vic3D to resolve the surface strain field.

\section{High Strain Rates}

A tensile Kolsky bar was adapted for testing polymer materials by coupling a $3.66 \mathrm{~m} 7075$ aluminum bar onto the end of the existing $2.74 \mathrm{~m} \mathrm{M} 300$ maraging steel system. This modification allowed for testing of softer materials by both extending the measurement duration for a longer loading pulse, as well as reducing the incident stresses imparted on the specimen. Experiments were limited to the smaller sized threaded specimens; ASTM specimens were not used because total displacements were on the order of a few millimeters. Pulse shaping was utilized to reduce oscillations in the bars, increase the pulse rise time to load the specimen, and encourage dynamic equilibrium. A schematic view of the tensile Kolsky bar is shown in Fig. 3. An impact gap is typically used to reduce reflections and ensure only a single loading pulse occurs in the specimen. However reflections could not be avoided due to the steel/aluminum interface in the incident bar. 
Fig. 3 Tensile Kolsky bar schematic diagram

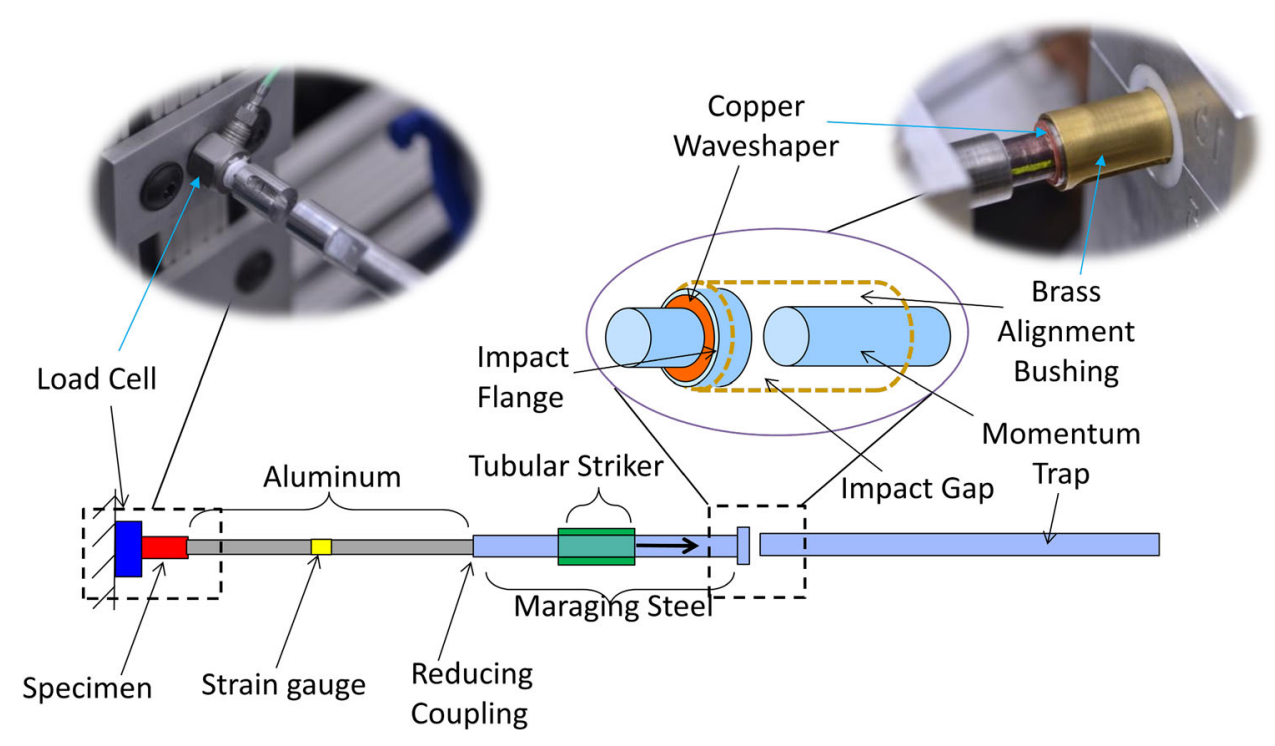

A pair of longitudinal strain gages are fixed to opposite sides of the bar circumference to record the impact pulse as it travels the length of the bar. These strain gages were used with a Vishay-Micro Measurements 2310B system that balanced the half Wheatstone bridge, provided gage excitation voltage, and amplified the strain signal at a bandwidth of approximately $300 \mathrm{kHz}$. A quartz based Kistler model 9212 piezoelectric load cell was rigidly fixed and measured the load on the output side of the specimen. Nominal values were determined using one-dimensional wave mechanics in the following equations originally derived by Kolsky [13]

$\varepsilon=-2 \frac{c_{0}}{L} \int_{0}^{t} \varepsilon_{r}(t) d t$

$\dot{\varepsilon}(t)=-\frac{2 c_{0}}{L} \varepsilon_{r}(t)$

$P=A_{b a r} E_{b a r} \varepsilon_{t}(t)$,

where $\varepsilon, c_{0}, L, t, \varepsilon_{r}, \dot{\varepsilon}, P, A_{b a r}, E_{b a r}$, and $\varepsilon_{t}$ denote strain, bar wave speed, specimen length, time, reflected pulse strain, strain rate, incident load, bar area, and bar modulus respectively. These global or nominal quantities were compared to those directly measured with DIC and the load cell at the specimen. Wave dispersion was neglected; high frequencies were filtered by pulse shaping and the combined incident bar was a relatively short length of approximately $6 \mathrm{~m}$. In order to record images for DIC at high framing rates, a Shimadzu HPV-2 camera was used at 125,000 frames per second. Images for high rate experiments were processed in Correlated Solutions Vic2D. As only a single camera of this type was available, strains were extracted along the centerline of the specimen to avoid any possible error in averaging a flat strain data field over a curved specimen surface.

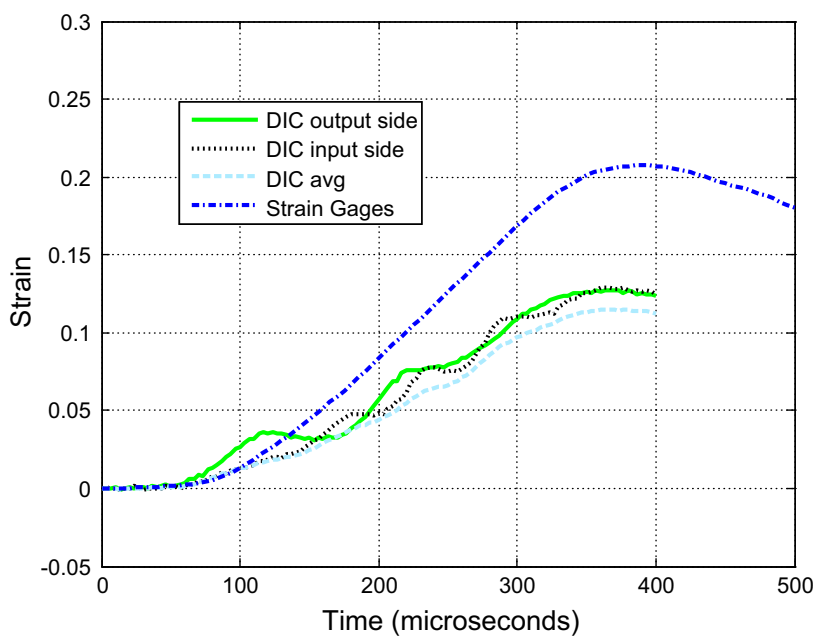

Fig. 4 DIC strain for different regions of threaded specimen in dynamic experiments

\section{Results}

\section{Modeling Efforts}

Initial high strain rate experiments with the threaded specimens of both materials gave unexpected results, with significant oscillation in the DIC strain measurement shown in Fig. 4. Unequal frequencies in the strain signals extracted from the DIC data at the input (7075 aluminum bar) and output (load cell) sides of the specimen were the main cause of concern. This disagreement in frequency indicated that these oscillations were in fact not due to the loading pulse nor wave reflections in the material. Complicated insertion and post-failure removal of the threaded specimens provided additional incentive for a specimen redesign. 
Finite element analyses of the threaded geometry were conducted using the explicit finite element code from Sandia National Laboratories, Sierra/Solid Mechanics [28]. Eight-node hexahedral elements were used in all analyses. The aluminum bars were modeled as purely elastic, with a bulk modulus of $76 \mathrm{GPa}$ and a shear modulus of $26 \mathrm{GPa}$. The PC specimen was modeled using a von Mises yield surface, with the yield stress determined by

$$
\begin{aligned}
\sigma_{Y}= & \left(A+B \varepsilon^{p} e^{-\frac{p}{\lambda}}+C\left(\varepsilon^{p}\right)^{n}\right)\left(1+D\left(T-T_{\text {room }}\right)\right. \\
& \left.+F\left(1-e^{\left(T-T_{\text {room }}\right)}\right)\right) .
\end{aligned}
$$

Here, $\varepsilon^{p}$ is the effective plastic strain, $T$ is the temperature, and the remaining symbols $\left(A, B, C, D, F, n, \lambda, \Gamma\right.$, and $\left.T_{\text {room }}\right)$ are material parameters. Note that the model includes strain hardening and thermal softening effects, but strain-rate effects were not included, as tensile rate effects are not well known and the intended numerical study lies within a fairly narrow rate regime. Mechanical parameters were fit from Moy et al. [29], and the thermal softening was taken to follow the shear modulus data from Mulliken and Boyce [10]. The yield surface parameters used for all analyses are

$A=50 \mathrm{MPa}, B=1.4 \mathrm{GPa}, C=97 \mathrm{MPa}, D=-0.002$,

$F=5 \times 10^{-9} n=2.5, \lambda=0.04, \Gamma=0.137$,

and $T_{\text {room }}=293 \mathrm{~K}$.

In addition, the bulk modulus of the PC was taken to be $3.1 \mathrm{GPa}$ and the shear modulus was taken to be $1.4 \mathrm{GPa}$.

The Kolsky tension bar was modeled using half of the incident bar and defining the acceleration on the surface corresponding to the center of the bar. The prescribed acceleration was computed from the strains observed at the strain gage at this location. Based on the pulses seen in experiments, a peak velocity $\left(V_{\max }\right)$ of $3 \mathrm{~m} / \mathrm{s}$ was achieved over a $175 \mu$ s rise time $\left(T_{\text {rise }}\right)$, with a dwell time of approximately $50 \mu$ s. Thus, the acceleration supplied was

$a(t)=\frac{\pi V_{\text {max }}}{2 T_{\text {rise }}} \sin \left(\frac{\pi t}{T_{\text {rise }}}\right)$.

The transmission bar is a short $(6 \mathrm{~cm})$ bar with a perfectly transmitting surface at the end (in essence, modeling an infinitely long bar). Loads were measured by integrating the stress on a cross-section of the transmission bar corresponding to the location of the load cell.

Initial simulations of the threaded specimen, with a perfectly mating specimen, did not reveal any oscillations, such as those seen in Fig. 4. However, when a small disagreement between the grip/specimen thread diameters was introduced, significant load oscillations occur, as shown in

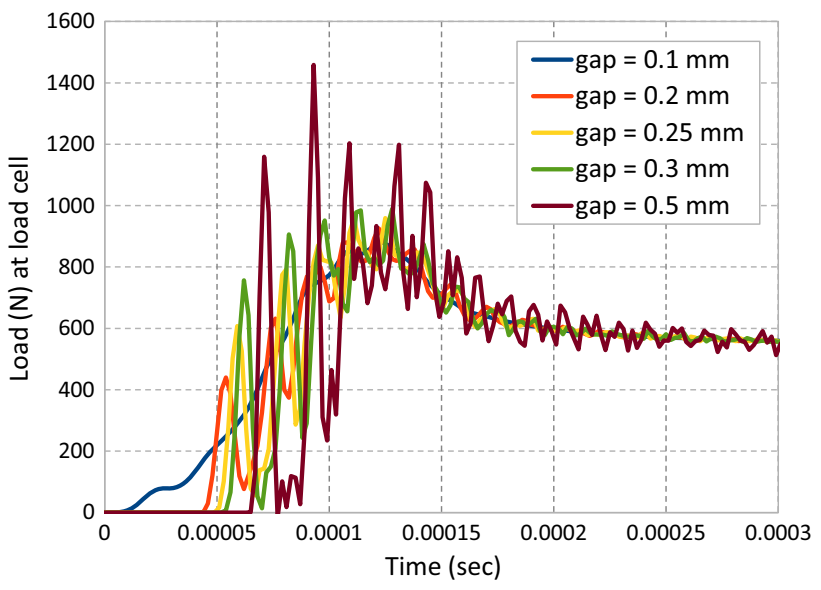

Fig. 5 Load versus time for threaded Kolsky tension specimens for various gaps in specimen thread diameter

Fig. 5. The "gap" in Fig. 5 is the decrease in outer diameter of the threaded section; during the simulation, the specimen was centered in the threaded section, resulting in space on both sides of the threads. These gap sizes (particularly in the $0.2-0.4 \mathrm{~mm}$ range) are typical of the variation in diameter measured in the machined samples. These oscillations are particularly troublesome for PC in the strain-softening regime where the load drops, causing some of the threads to lose contact (or even load on the reverse side). Changes in the thread pitch resulted in even more complex results, with both load and strain oscillations depending on both the amplitude and location of the pitch variation.

Considering the difficulty of exactly threading each specimen in order to produce both accurate and repeatable results, it was decided that a new specimen geometry should be implemented. The general concept of the conical specimen in Fig. 6 was proposed with similar gage lengths to the threaded specimen, but the grip angle and the overall length were undetermined. A flat sided cross section was included in the gripping region in order to facilitate specimen insertion and removal from the grips. This desired feature greatly increased operator efficiency over that of the earlier threaded design. Simulations of $10^{\circ}, 15^{\circ}, 20^{\circ}$, and $30^{\circ}$ conical grip angles were initially conducted; it was quickly determined that a $10^{\circ}$ grip angle resulted in extrusion through the hole in the grips for any reasonable value of the coefficient of friction $(<0.5)$, indicating that significant straining was occurring in the grip volume. The $15^{\circ}$ specimen showed a small amount of plastic strain in the grip volume, while the $20^{\circ}$ and $30^{\circ}$ specimens showed no plastic strain in the grip volume. The grip length was then systematically varied for the $20^{\circ}$ specimen, and it was found that a grip length greater than 1.5 times the gage length provided sufficient grip area to prevent any yielding in the gripping region of the specimen. The final specimen 


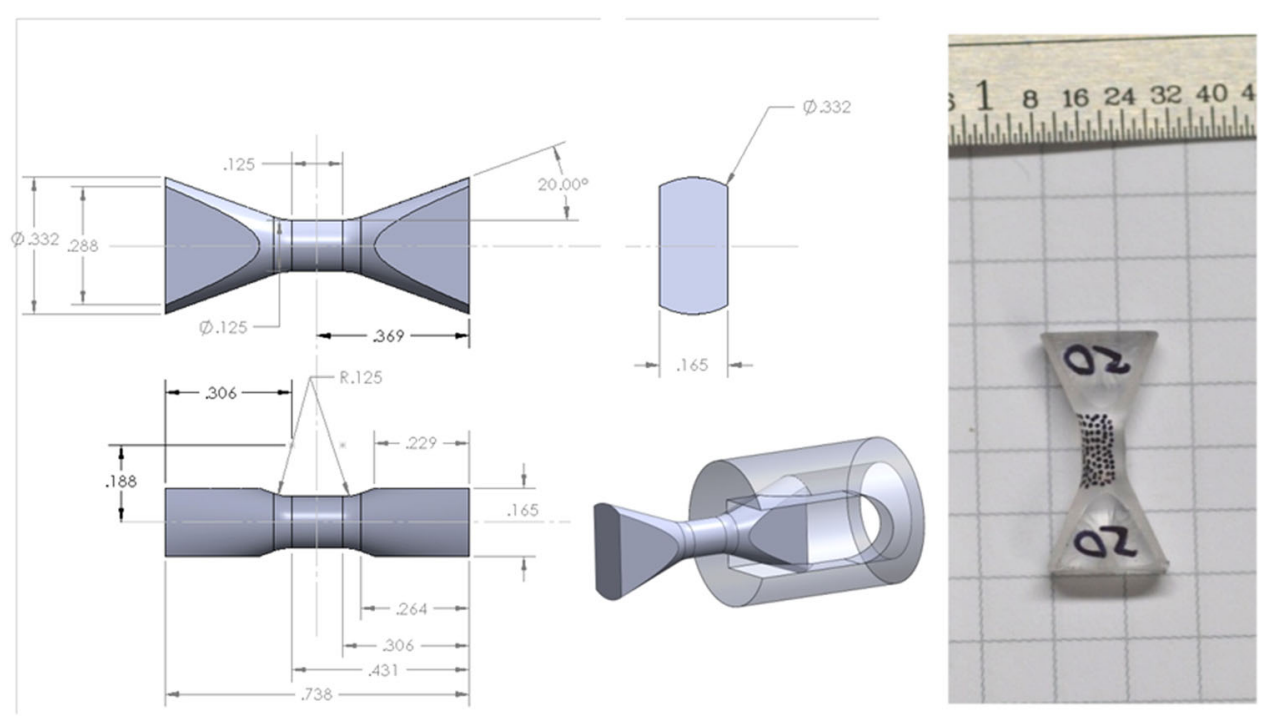

Fig. 6 Novel conical type specimen

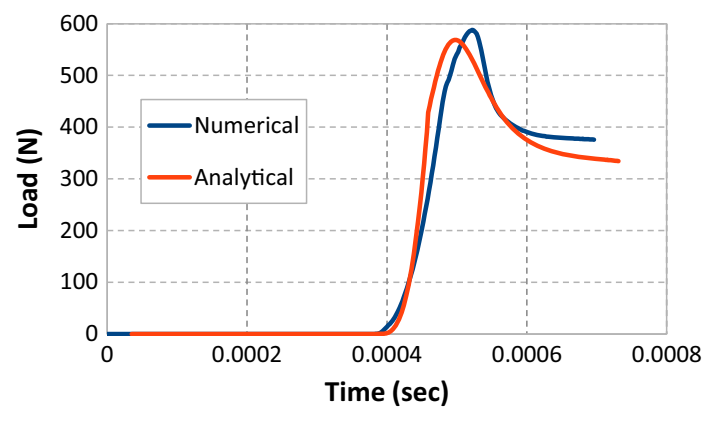

Fig. 7 Load versus time for $20^{\circ}$ conical specimen

was then chosen to have a grip length of approximately two times the gage length, as seen in Fig. 6.

The simulation of the resulting specimen generated the load versus time curve shown in Fig. 7. Note the absence of any oscillations during the entire simulation including the strain-softening region. The analytical solution assumes a homogeneous deformation over the gage section and the analytical elastic-plastic solution is evaluated for this deformation. The simulation and subsequent experiments showed that the strain is not uniform, resulting in the discrepancy between the analytical and numerical model. Nevertheless, the result is a specimen geometry that is simple to fabricate, is repeatable, and eliminates the spurious oscillations seen in the threaded specimens.

\section{Quasi-Static \& Intermediate Experiments}

ASTM D638 Type III specimens were tested under quasistatic conditions to validate the newly designed conical specimen. A comparison of these specimens to the new designs is included in Fig. 8. The similar flow stresses and deformation behavior shows a good correspondence between the ASTM Type III standard specimen and new conical designs. Conical specimens showed a reduced initial modulus compared to the ASTM design in the subsets of Fig. $8 \mathrm{a}$ and $\mathrm{b}$. This reduction in stiffness could be attributed to a much greater portion of the specimen volume being contained in the gripping region, where it is assumed a small amount of elastic deformation occurs. Nonetheless, the true stress in the conical specimen is seen to surpass that of the ASTM specimen to give a slightly higher yield stress with a more pronounced peak in that region. These curves are from single experiments, and the individual variation was found to be small compared to the difference between the conical and ASTM specimen designs.

\section{Dynamic Experiments}

Results from a typical experiment for a conical PC specimen are seen in Fig. 9. Two distinct pulses (incident and reflected) of similar shape and duration are apparent in the signals from the incident bar strain gage signal in Fig. 9a, which demonstrates that the loading pulse was supplied to the specimen in full duration without any wave overlap. Wave reflections from the steel-aluminum bar interface arrived after approximately $1800 \mu \mathrm{s}$ in Fig. 9a, after the reflected pulse has ended. An observed constant strain rate of $1600 \mathrm{~s}^{-1}$ is also measured from the strain gages as a constant plateau from 300 to $450 \mu \mathrm{s}$ in Fig. 9b. The disagreement between the strain measured by the strain gages and DIC in Fig. 9c demonstrates the necessity of local measurements; the strain field (Fig. 10) shows that significant localization occurs that is not captured solely by grip displacement. DIC true strain measurements 

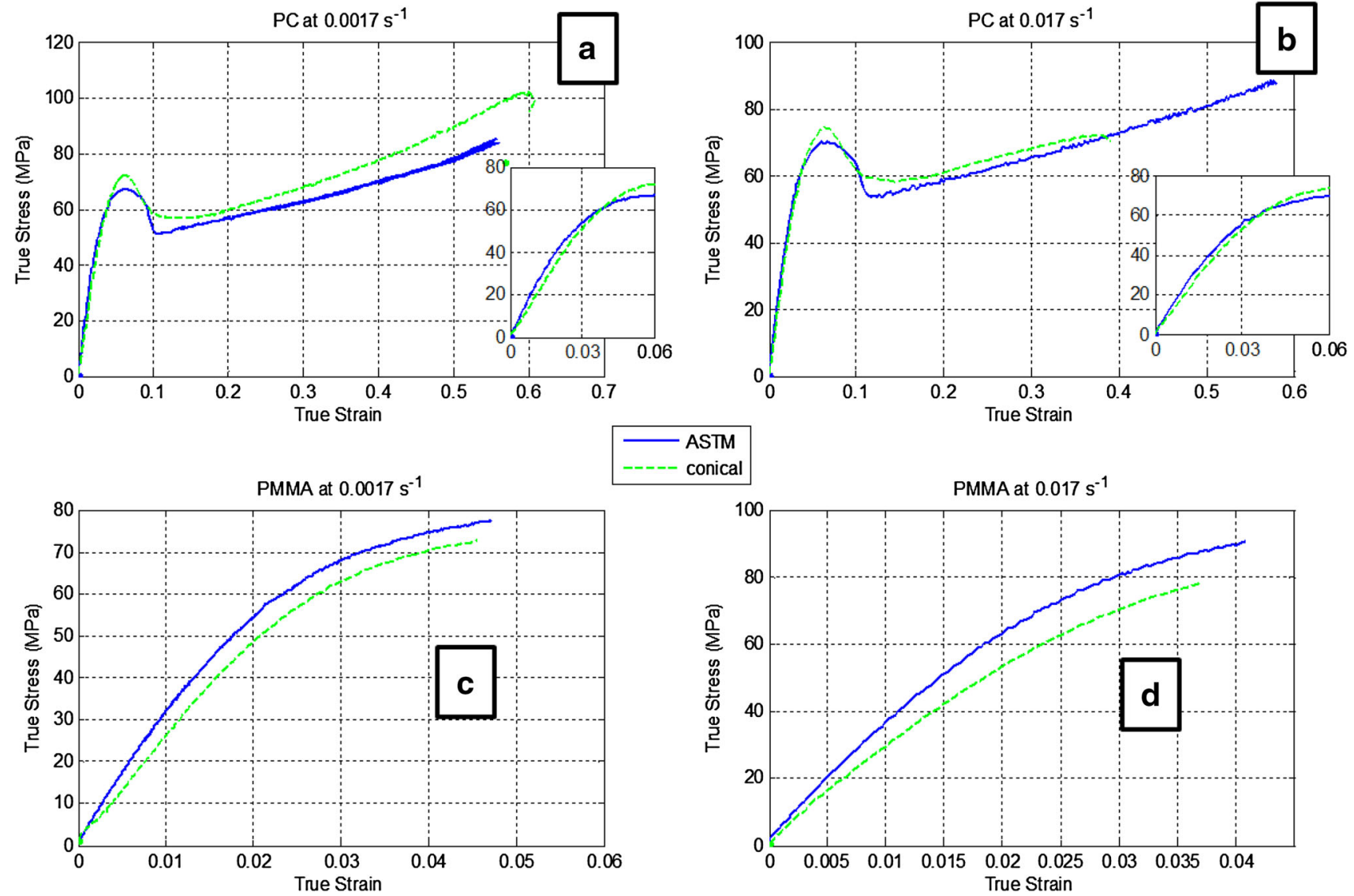

Fig. 8 Comparison of ASTM D638 Type III specimens to conical specimens for PC at a $0.0017 \mathrm{~s}^{-1}$ and $\mathbf{b} 0.017 \mathrm{~s}^{-1}$ as well as for PMMA at c $0.0017 \mathrm{~s}^{-1}$ and d $0.017 \mathrm{~s}^{-1}$

were therefore used for stress-strain response in all subsequent analyses, with strain gages only used to monitor the experiment and for comparison to existing published data. Full-field measurements on the specimen surface can account for any localized deformation that occurs in the gage section, which is often significant for soft polymers. Figure 9d clarifies that when the incident and reflected pulses are subtracted to obtain the transmitted pulse and compared to the load measured by the load cell, dynamic equilibrium was achieved.

The DIC strain data shows an evident time delay when compared to the engineering strain calculated from the bar end displacement. This disagreement corresponds to the sharp peak in load calculated from the strain gage signal in Fig. 9d at approximately $280 \mu$ s which is attributed to the load required to apply a high initial acceleration to the specimen. Despite this peak, the close agreement between the input load calculated from the strain gages and output load from the load cell is adequate to ensure the specimen is in dynamic equilibrium. This is especially the case in the region around $400 \mu \mathrm{s}$.

The high rate tensile experiments showed that permanent deformation occurred in the gage length of the conical PC specimens. Processed DIC images in Fig. 10 further clarify that strain did localize and necking occurred in the gage section for these high strain rate experiments.

The measured material response of PC for this single experiment is shown in Fig. 11. Once again it is verified that plastic deformation did take place, and a clear peak stress or instability point can be seen to be $105 \mathrm{MPa}$. Some small oscillations occur in the elastic region, but at a very small level of strain. These are likely due to ringing in the specimen as the high rate of acceleration is imparted to the polymer specimen through the grips and any oscillation is eliminated once plastic deformation occurs after approximately $5 \%$ strain.

When compared to results on PC, PMMA had reached full failure at lower strain levels with no noticeable plastic deformation. Figure 12a shows two separate pulse profiles as before, and the specimen was again subjected to a constant strain rate up until failure at approximately $390 \mu \mathrm{s}$ in Fig. 12b. This nominal strain rate measured by the strain gages is $800 \mathrm{~s}^{-1}$. The comparison of DIC strain to the traditional incident bar strain gage measurement illustrates a vast difference in Fig. 12c. This large disparity in strain reflects the low strain to failure of PMMA, especially when 

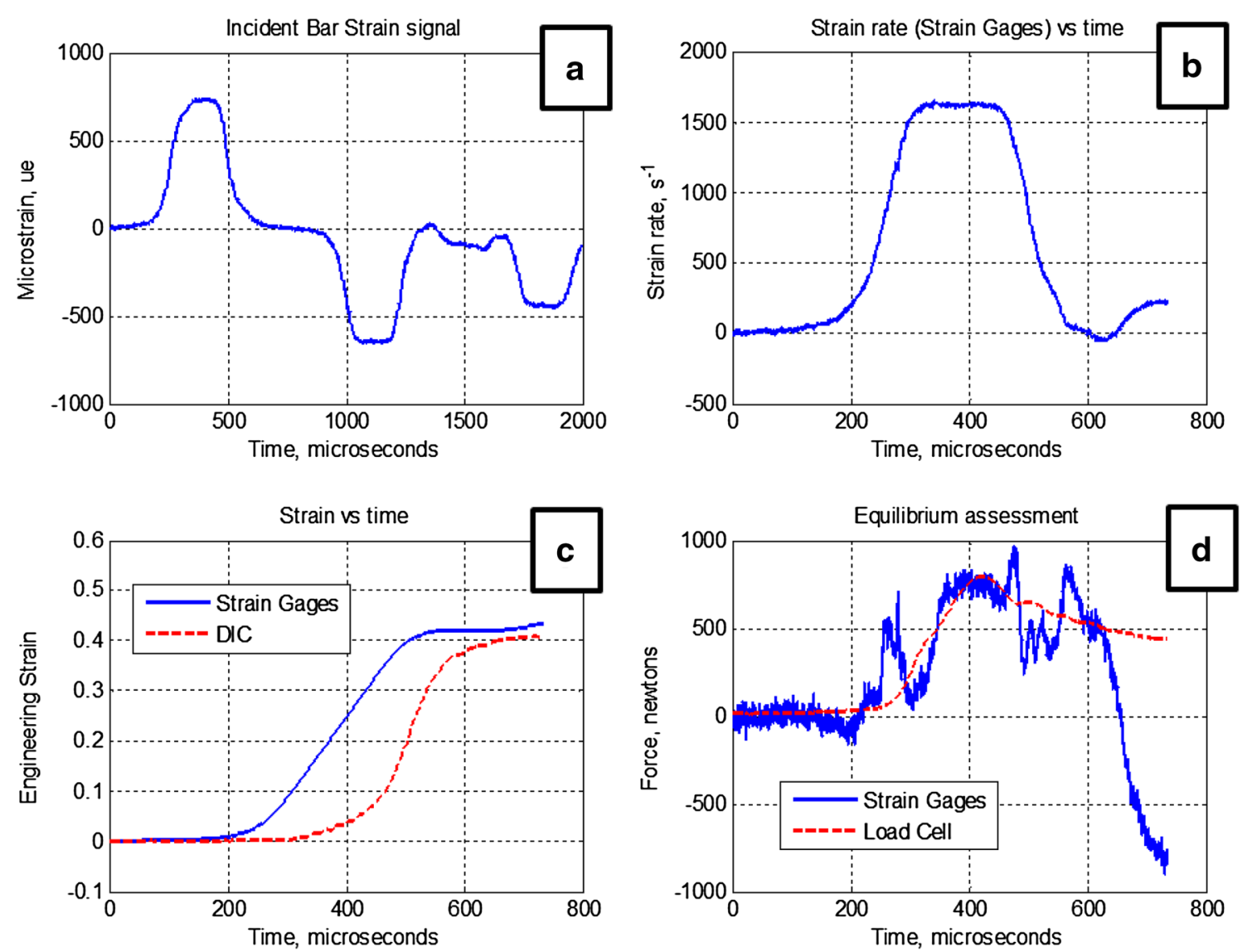

Fig. 9 PC tensile results from a Kolsky bar experiment at $1600 \mathrm{~s}^{-1}$ strain rate
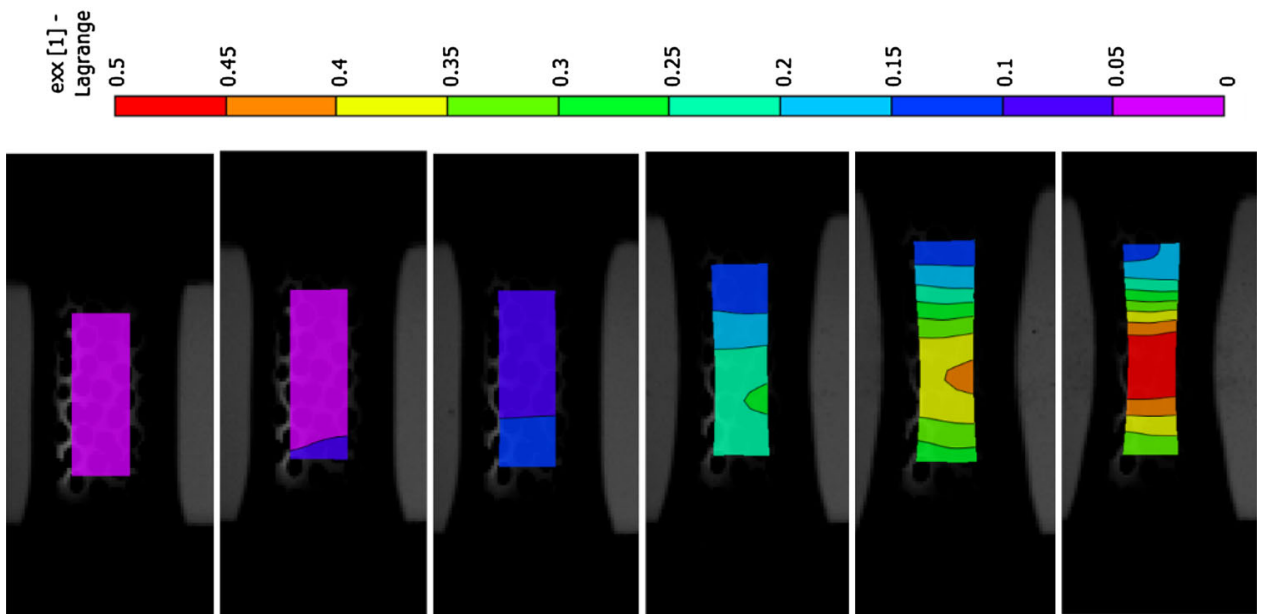

Fig. 10 DIC images (rotated) indicate plastic behavior in gage region for PC in Kolsky bar experiments

Fig. 12c is compared to Fig. 11c. Dynamic equilibrium has been verified in Fig. 12d with both the load calculated from input bar end displacement and output load cell showing good agreement.

The low strain to failure of PMMA is clarified in images captured for the DIC measurement; these are again included in Fig. 13 to verify that the specimen behavior was purely elastic. No clearly defined pattern emerges and the relatively low strain is seen to be much more homogeneous throughout the specimen.

Oscillations were measured in the stress-strain material response of PMMA in Fig. 14. This data is once again for a single experiment. While not necessarily clear in the DIC overlay pattern in Fig. 13, the low overall strain to failure 
of PMMA makes these small variations much more prominent. These oscillations are an artifact of high strain rate experiments where the wave speed of the material is on the order of the loading rate. In this case, local DIC measurements provided a direct measurement of the material behavior, for these oscillations would not be seen if the

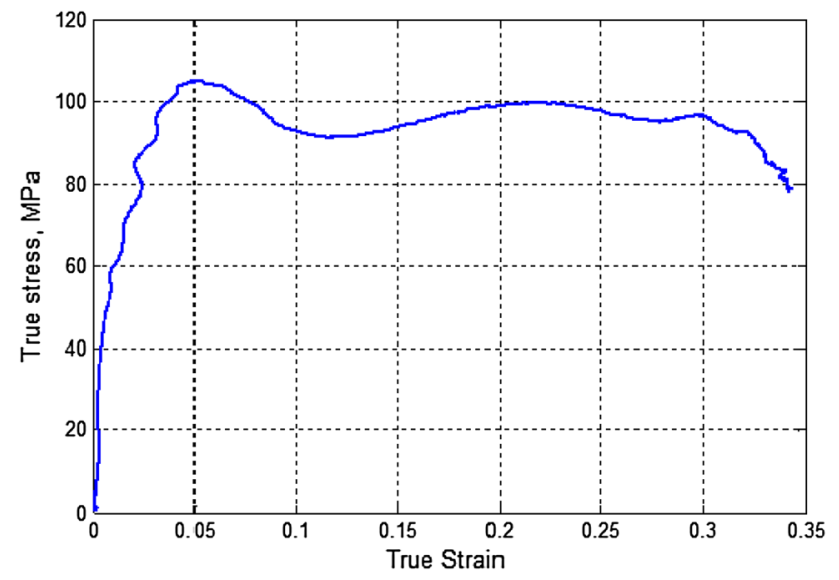

Fig. 11 True stress-strain material response for single experiment of $\mathrm{PC}$ at high strain rate
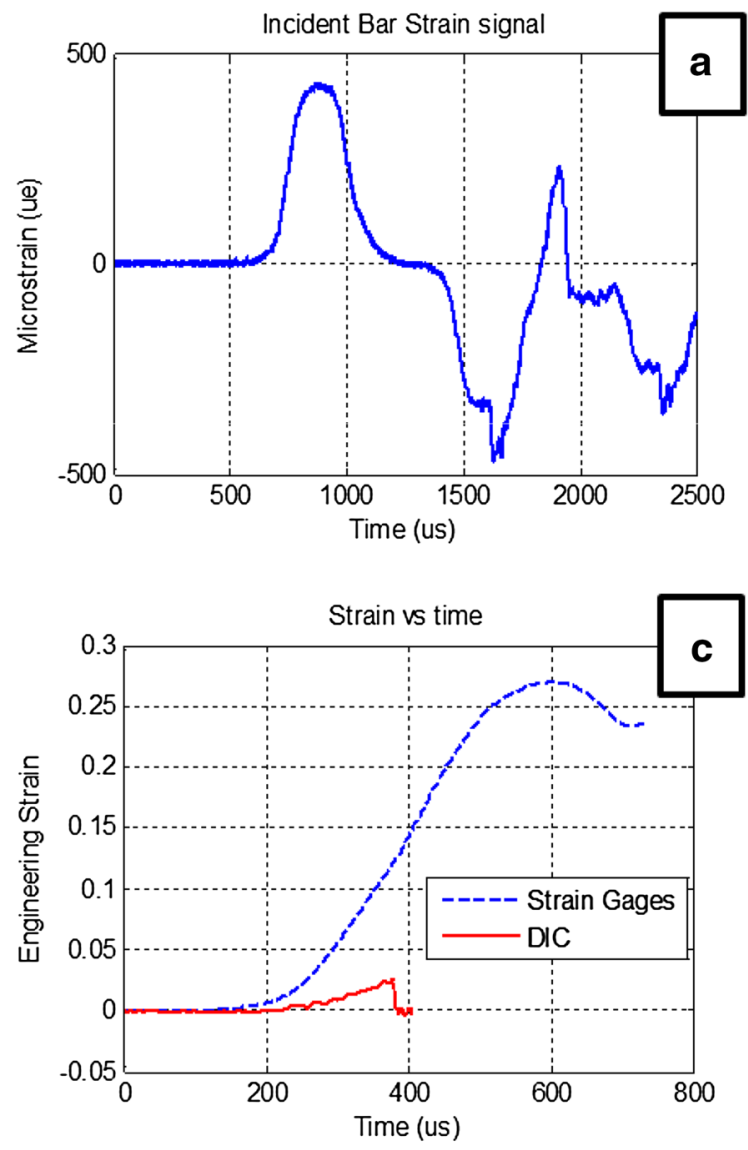

strain were measured using the incident bar strain gages, such as in Fig. 12c.

\section{Discussion}

\section{Strain and Strain Rate}

For all experiments it was found that the actual engineering strain rate measured using DIC differed from the desired engineering strain rate derived from the grip displacement. At each strain rate studied, the DIC strain rate was found to be lower than that calculated from the machine displacement. Both PC and PMMA closely followed a linear relationship between the DIC strain rate and strain rate derived from the grip displacement in Fig. 15, as the exponential of the trendline is seen to be very close to unity. Data groups for each sample have been plotted in this and subsequent figures as crosses, with the average at the cross intersection and outliers in both positive and negative $\mathrm{x}$ and $\mathrm{y}$ axes representing the horizontal and vertical arms respectively. A smaller overall cross would therefore describe much higher precision and reduced scatter.
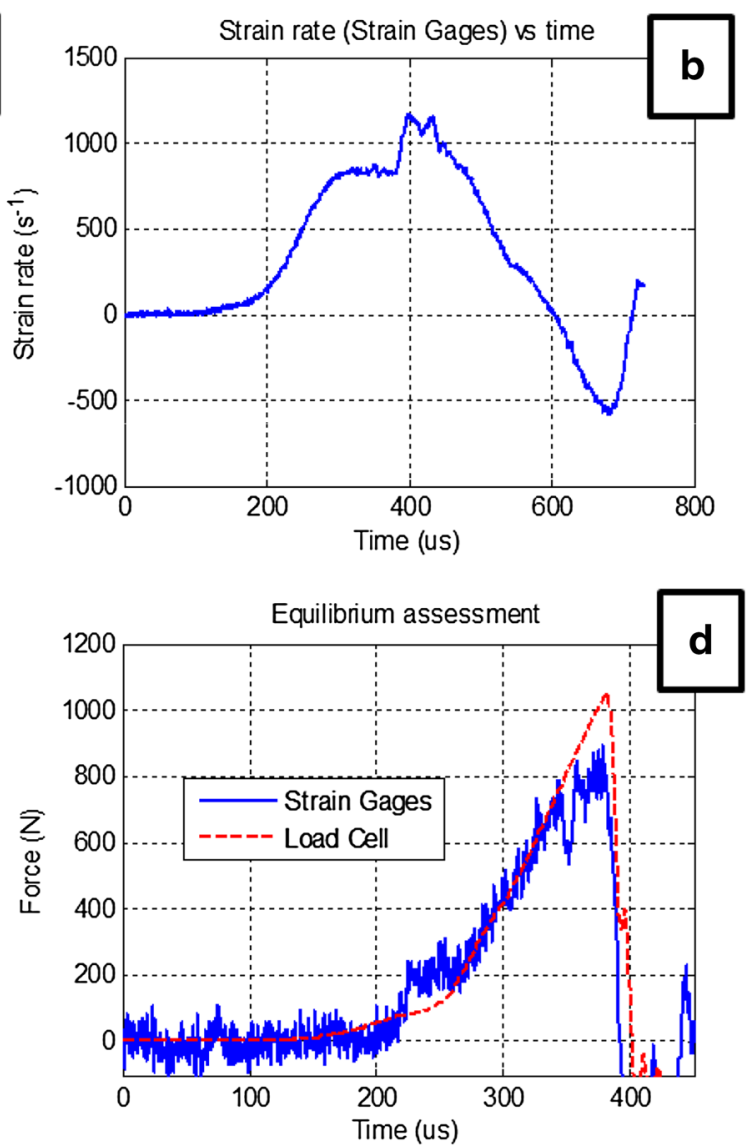

Fig. 12 PMMA tensile results from a Kolsky bar experiment at $800 \mathrm{~s}^{-1}$ strain rate 

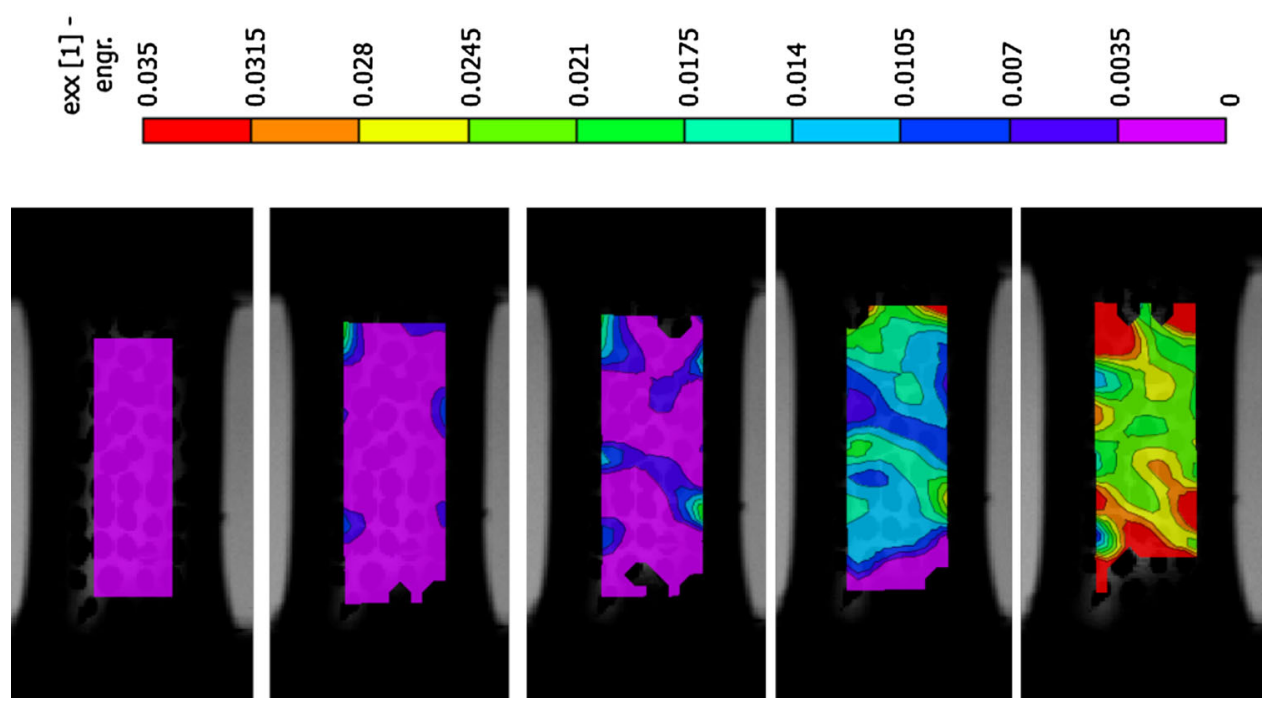

Fig. 13 DIC images (rotated) give homogeneous strain in gage region for PMMA in Kolsky bar experiments

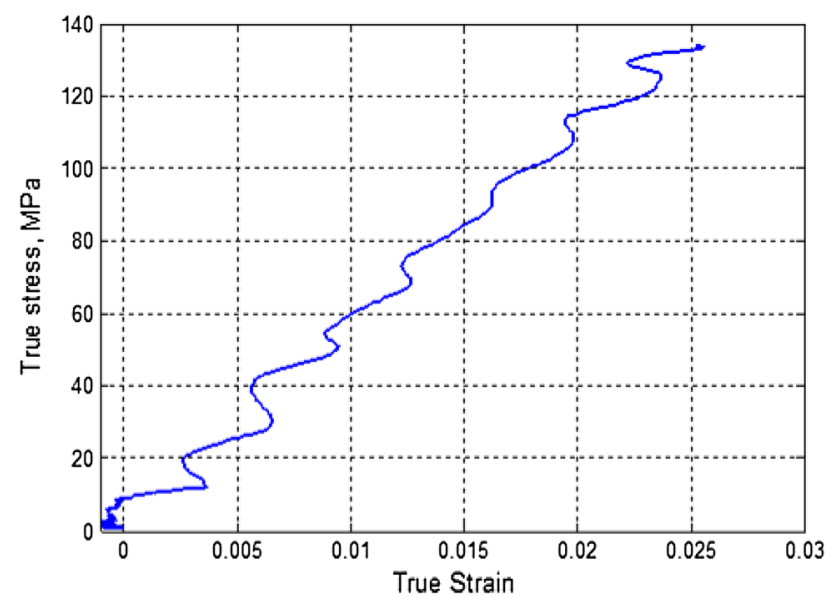

Fig. 14 True stress-strain material response for single experiment of PMMA at high strain rate

Uncertainties in both stress and strain give rise to a range of values at each strain rate. Load cells used at all strain rates had an innate noise floor, with the original recorded value finally measured through an analog to digital converter of 16 bit resolution. However, the uncertainty of a DIC measurement is not as simple. All typical factors involved in an optical measurement system such as illumination, image resolution, framerate, and focus affect the accuracy as well as the underlying assumptions of the image processing algorithm [30].

The reduction in achieved strain rate in Fig. 15 is from elastic deformations that occur in the conical gripping region of the new specimen design, which would reduce the overall strain when compared to the grip separation. When the gripping section constitutes a large portion of the overall specimen volume, local measurements are critical in accurately measuring the strain and strain rate. This is analogous to Figs. 9c and 12c where the strain gages underestimate the engineering strain rate for high strain rate experiments. The traditional method of deriving strain rate was found to be largely inaccurate for PC because not only does it ignore elastic deformation in the gripping region, it also fails to describe any necking and local deformation behavior in the gage length.

While PMMA exhibited homogeneous strains throughout the specimen gage length, the complicated plastic behavior of PC requires true strain values to be adequately characterized. Figure 16 also shows that the strain rate during plastic strain hardening in PC is typically one order of magnitude higher than the elastic remainder of the experiment for all rates considered.

\section{Instability Stress in PC}

Polycarbonate typically undergoes an instability point, where the flow stress decreases as the material begins to neck with increasing strain. The inset of Fig. 17 has this point of the stress strain curve circled for clarification. This instability stress point showed an increase with the strain rate and good agreement with published engineering stress-strain values from both $\mathrm{Cao}$ [3] and $\mathrm{Fu}$ [7] as shown in Fig. 17. The strain rates here are those derived from machine displacement and not DIC in order to give a direct comparison to published values. Corresponding DIC measured strain rates can be inferred from Fig. 15. While the variation in instability stress at dynamic rates in Fig. 17 is large compared to other rates considered, the variation is well within an acceptable and expected range for dynamic experiments. Unlike PC, PMMA specimens did not show 


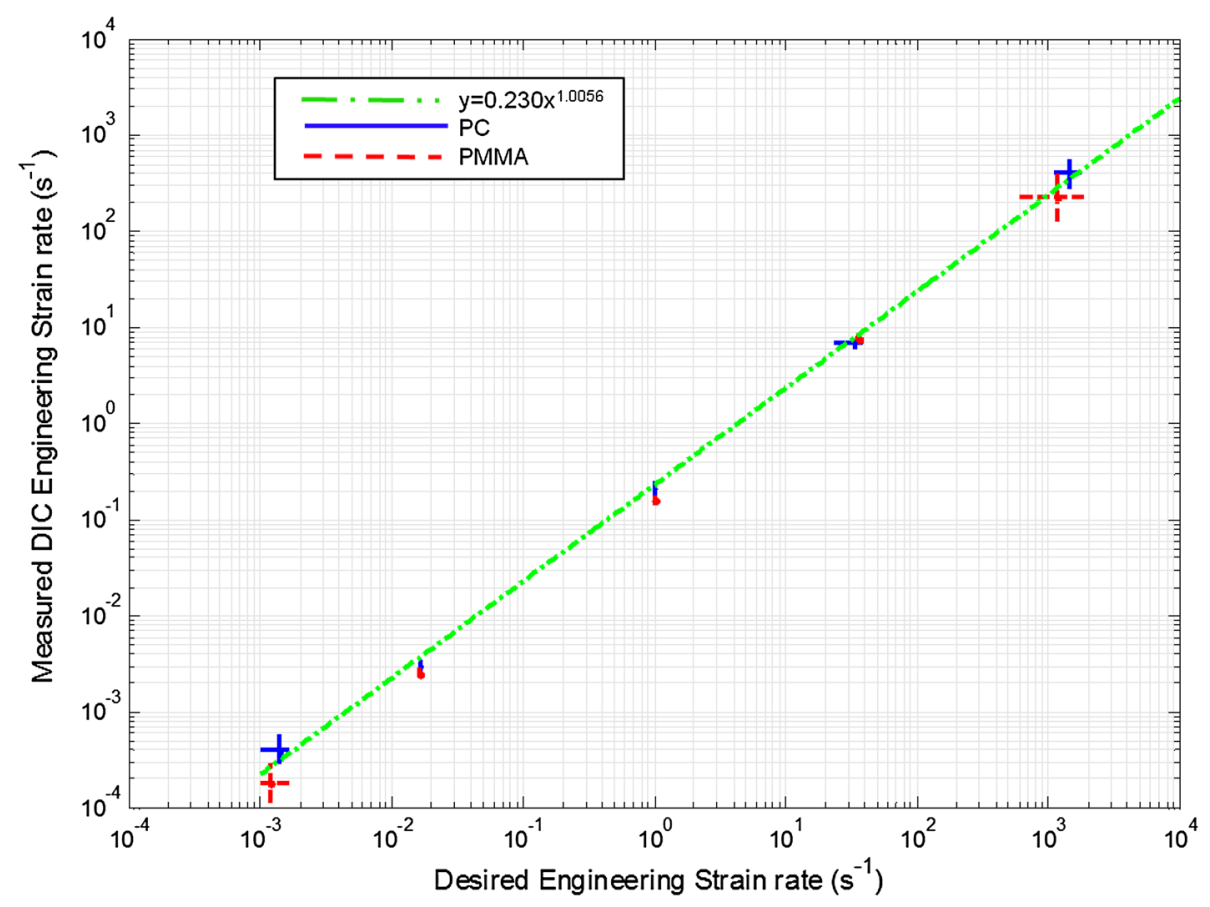

Fig. 15 Measured versus desired strain rate for all experiments on conical specimens

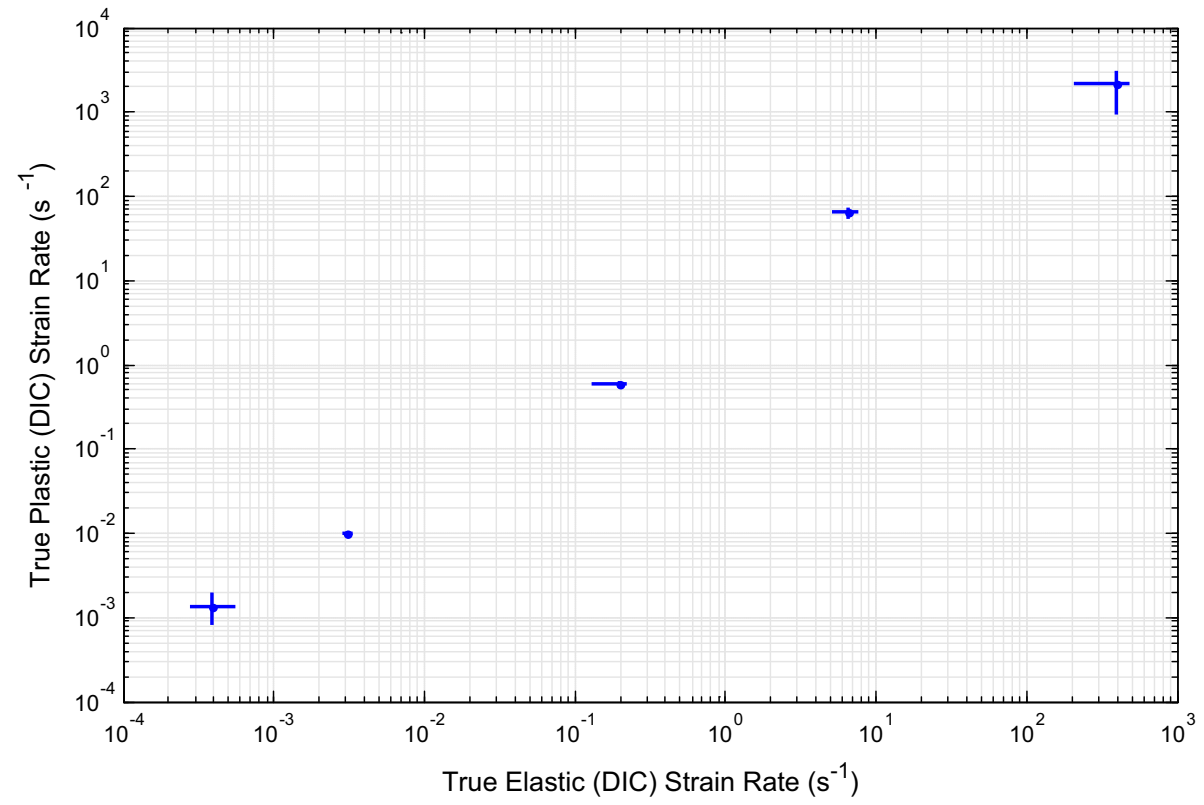

Fig. 16 Strain rate in post-yield plastic response versus strain rate in elastic response for PC

plastic behavior at any strain rate and underwent brittle failure in all of the tensile tests.

\section{Modulus}

Modulus values for PC at low strain rate showed good agreement to those published by $\mathrm{Cao}$ [3] and $\mathrm{Fu}$ [7] as well.
In Fig. 18, the modulus was relatively constant with a small decrease at the intermediate rate of $100 \mathrm{~s}^{-1}$, then rose to a maximum at high strain rate. This agrees with other researchers that material stiffness increases after a rate-dependent viscoelastic transition [10]. However, other researchers did not see as pronounced an increase in modulus at high strain rates as measured here. 


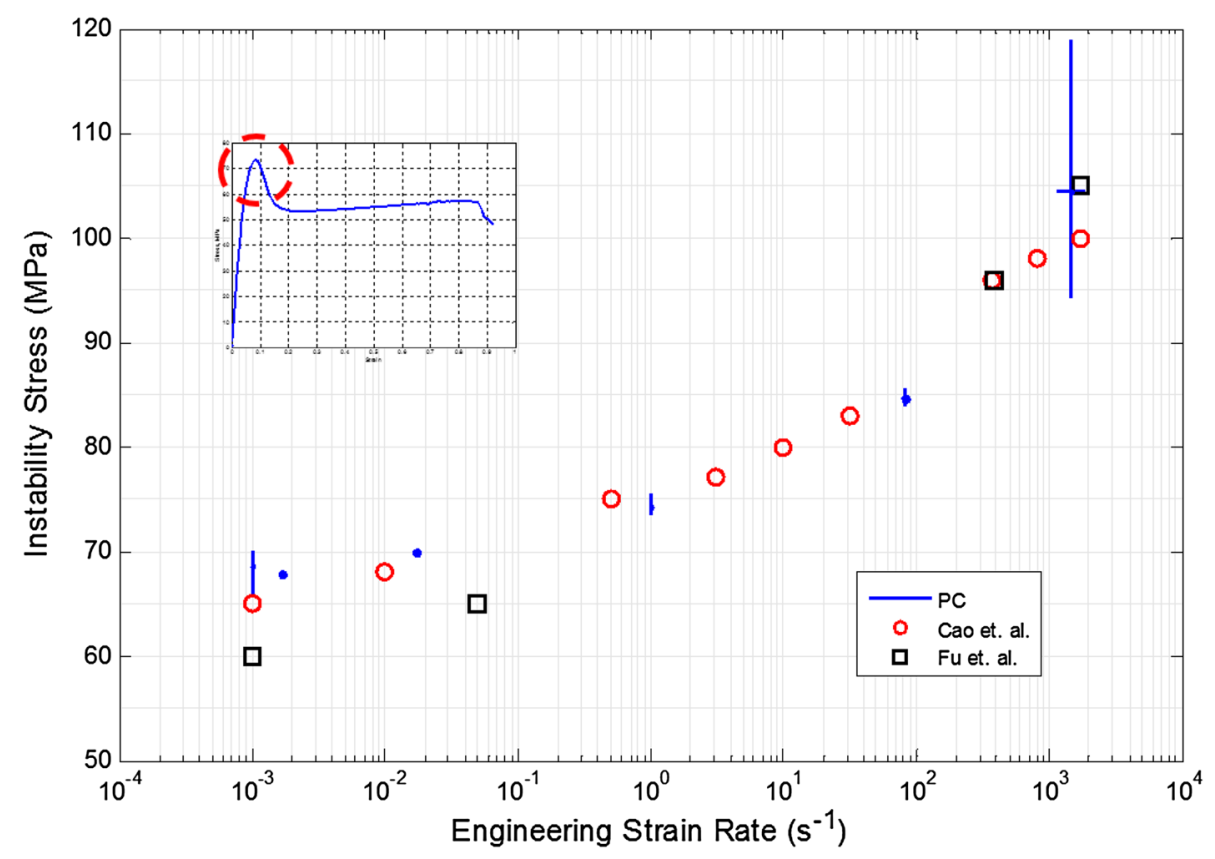

Fig. 17 Engineering stress at instability point for all (elastic) strain rates for PC

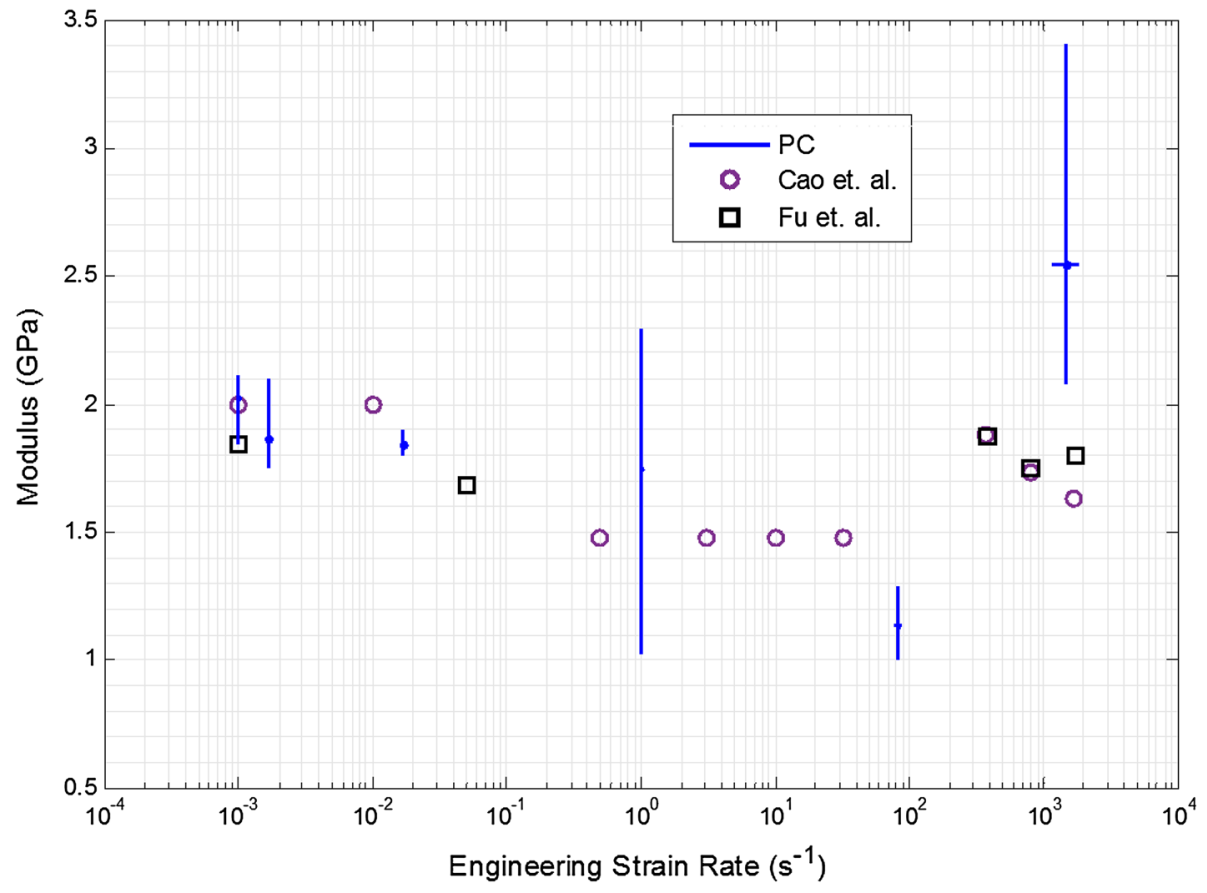

Fig. 18 Engineering stress-strain tensile modulus as a function of strain rate for PC

Once again, measured engineering stress-strain modulus values for PMMA in Fig. 19 agreed with those published by $\mathrm{Wu}$ [30]. However, this trend diverges in the intermediate regime, where PMMA gave a decreased stiffness in similar fashion to PC. Wu did not give any recordings of direct measurements nor show any verification of a custom intermediate rate test apparatus, so any conclusions regarding this disagreement would prove difficult.

Chen [2] however used true stress-strain values to measure the dynamic response of PMMA in tension, and those findings are compared to measurements done here in Fig. 20. While similar, a large discrepancy is obvious at high rates. For this case, the difference in modulus can be 


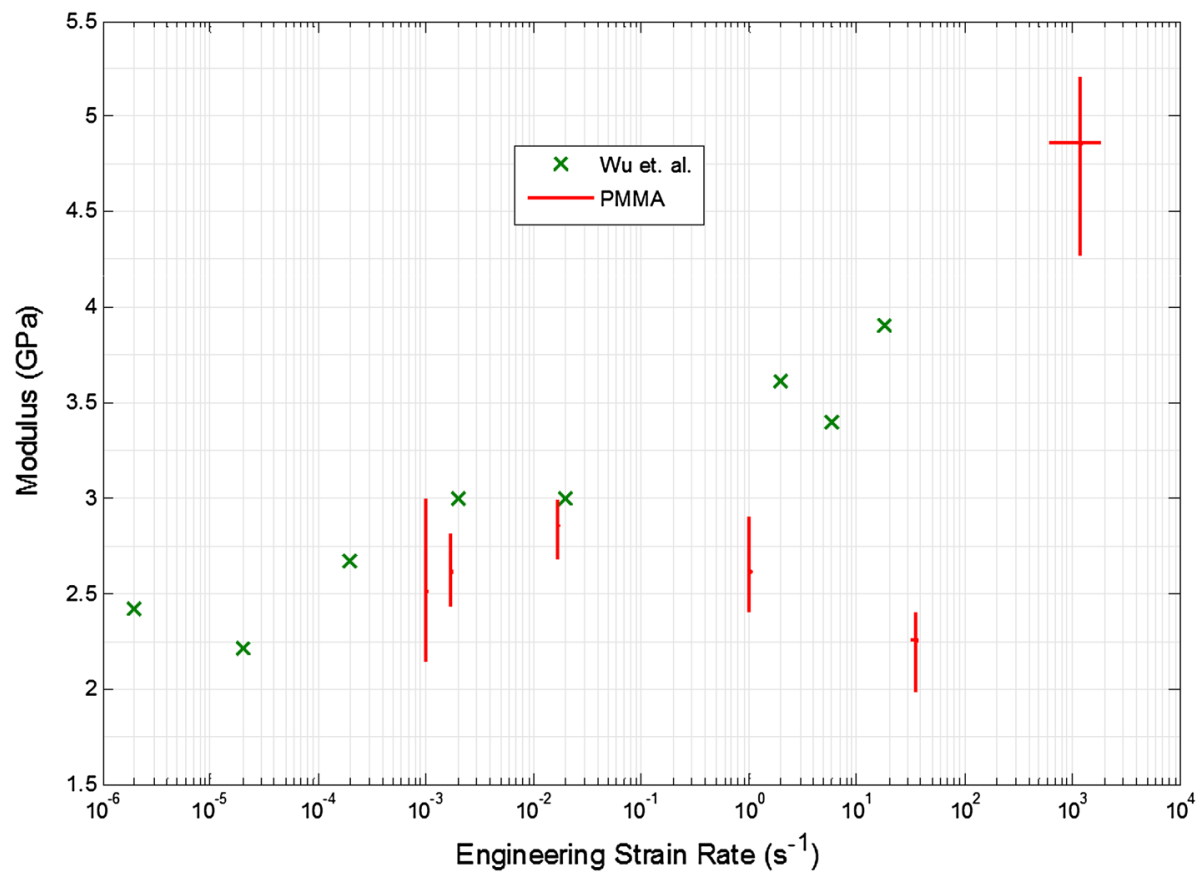

Fig. 19 Engineering stress-strain tensile modulus as a function of strain rate for PMMA

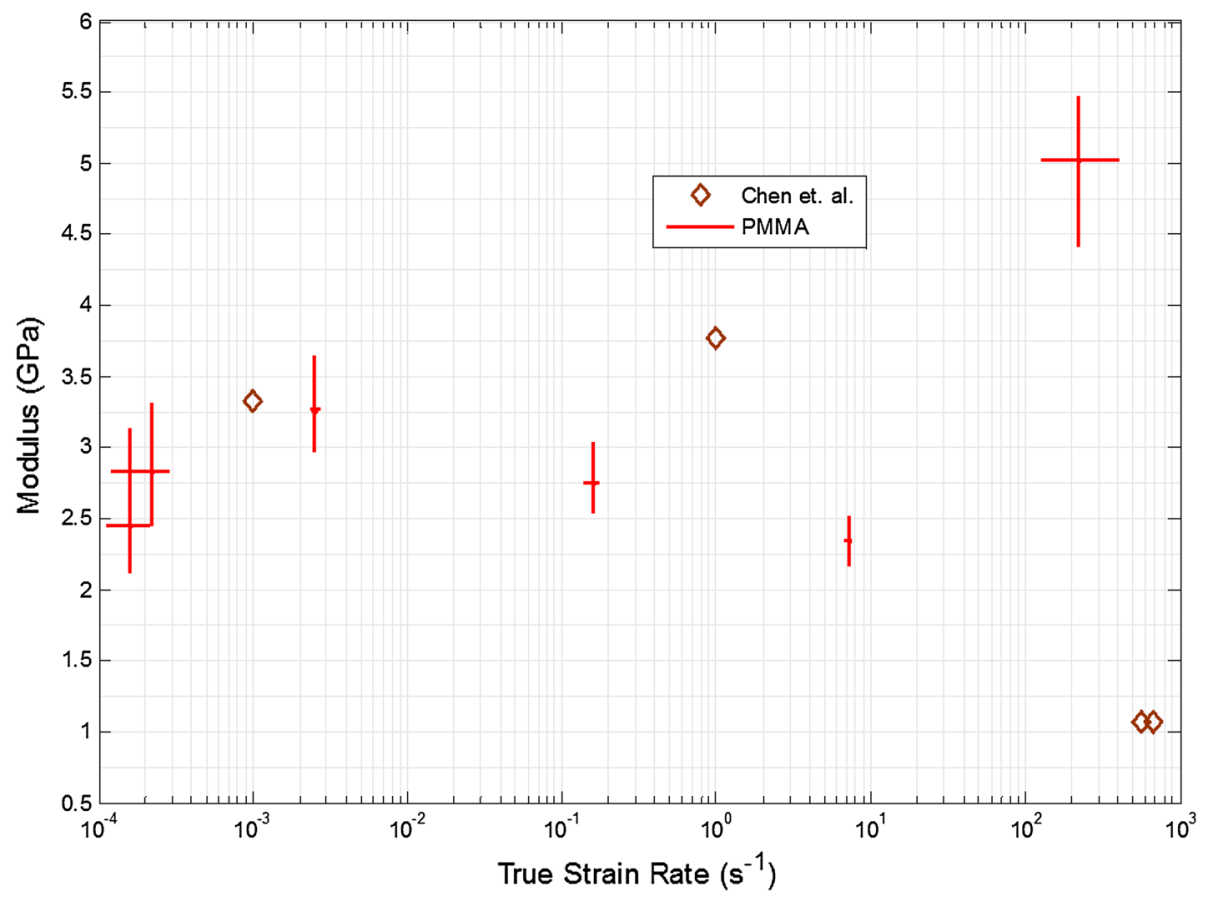

Fig. 20 True stress-strain tensile modulus as a function of strain rate for PMMA

attributed to the disagreement between the engineering strain derived from machine displacement and that measured by DIC in Fig. 12c. The DIC strain measurement is a more accurate strain measurement in this case, and this difference between measured values and those previously published further elucidates this fact.

\section{Summary}

Tensile experiments at various strain rates provide insight into the behavior of amorphous polymers that is unlike their compressive behavior. Experiments at high strain rates using existing specimen geometry showed load 
oscillations that were verified by a material model. These errors were alleviated with a new specimen design that also simplifies fabrication, minimizes stress concentrations, and increases gripping surface area. This conical specimen design was shown to be equivalent to the ASTM standard as well as effective for both ductile and brittle polymers for all strain rates from the quasi-static to dynamic regimes. A similar trend was seen for PC and PMMA throughout strain rates, with moduli remaining relatively constant up until intermediate rate with a subsequent increase at high strain rates. Unlike PC, PMMA gave consistent brittle failure at all strain rates studied. Local measurements are proven to be critical in capturing the tensile behavior of PC, which exhibits strain-softening and localization that invalidates many traditional engineering measurements of strain. Future work includes full field thermography, which can provide experimental data for a coupled thermomechanical constitutive model.

Acknowledgments The authors would like to acknowledge Mr. Steven Ghiorse for performing ASTM D638 tension experiments.

\section{References}

1. ASTM D638-14 (2014) Standard test method for tensile properties of plastics. ASTM International, West Conshohocken, PA. doi:10.1520/D0638-14

2. Chen W, Lu F, Cheng M (2002) Tension and compression tests of two polymers under quasi-static and dynamic loading. Polym Testing 21:113-121. doi:10.1016/S0142-9418(01)00055-1

3. Fu S, Wang Y, Wang Y (2009) Tension testing of polycarbonate at high strain rates. Polym Test 28:724-729. doi:10.1016/j.poly mertesting.2009.06.002

4. Sarva S, Boyce M (2007) Mechanics of polycarbonate during high rate tension. J Mech Mater Struct 2(10):1853-1880. doi:10. 2140/jomms.2007.2.1853

5. Rae P, Brown E (2005) The properties of poly(tetrafluoroethylene) (PTFE) in tension. Polymer 46:8128-8140. doi:10.1016/j.polymer.2005.06.120

6. Dwivedi A, Bradley J, Casem D Mechanical response of polycarbonate with strength model fits. ARL-TR-5899 2012

7. Cao K, Ma X, Zhang B, Wang Y, Wang Y (2010) Tensile behavior of polycarbonate over a wide range of strain rates. Mater Sci Eng A 527:4056-4061. doi:10.1016/j.msea.2010.03.088

8. Bauwens J (1972) Relation between the compression yield stress and the mechanical loss peak of bisphenol-A-polycarbonate in the $\beta$ transition range. J Mater Sci 7:577-584. doi:10.1007/BF00761956

9. Bergstrom J, Boyce M (1998) Constitutive modeling of the large strain time-dependent behavior of elastomers. J Mech Phys Solids 46(5):931-954. doi:10.1016/S0022-5096(97)00075-6

10. Mulliken A, Boyce M (2006) Mechanics of the rate-dependent elastic-plastic deformation of glassy polymers from low to high strain rates. Int J Solids Struct 43:1331-1356. doi:10.1016/j. ijsolstr.2005.04.016

11. Richeton J, Ahzi S, Vecchio K, Jiang F, Makradi A (2007) Modeling and validation of the large deformation inelastic response of amorphous polymers over a wide range of temperatures and strain rates. Int J Solids Struct 46:7938-7954. doi:10.1016/j. ijsolstr.2007.05.018
12. Safari K, Zamani J, Ferreira F, Guedes R (2013) Constitutive modeling of polycarbonate during high strain rate deformation. Polym Eng Sci 53(4):752-761. doi:10.1002/pen.23315

13. Kolsky H (1949) An Investigation of the mechanical properties of materials at very high rates of loading. Proc Phys Soc B 62(11):676-700. doi:10.1088/0370-1301/62/11/302

14. Wang L, Labibes K, Azari Z, Pluvinage G (1994) Generalization of split Hopkinson bar technique to use viscoelastic bars. Int J Impact Eng 15(5):669-686. doi:10.1016/0734-743X(94)90166-I

15. Zhao H, Gary G, Klepaczko J (1997) On the use of a viscoelastic split Hopkinson pressure bar. Int J Impact Eng 19(4):319-330. doi:10.1016/S0734-743X(96)00038-3

16. Bacon C, Brun A (2000) Methodology for a Hopkinson test with a non-uniform viscoelastic bar. Int J Impact Eng 24:219-230. doi:10.1016/S0734-743X(99)00166-9

17. Follansbee P, Frantz C (1983) Wave propagation in the split Hopkinson pressure bar. J Eng Mater Technol 105(1):61-66. doi:10.1115/1.3225620

18. Lundberg B, Henchoz A (1977) Analysis of elastic waves from two-point strain measurement. Exp Mech 17(6):213-218. doi:10. 1007/BF02324491

19. Frew D, Forrestal M, Chen W (2005) Pulse shaping techniques for testing elastic-plastic materials with a split Hopkinson pressure bar. Exp Mech 45(2):186-195. doi:10.1177/001448510 5052111

20. Vecchio K, Jiang F (2007) Improved pulse shaping to achieve constant strain rate and stress equilibrium in split Hopkinson pressure bar testing. Metall Mater Trans A 38(11):2655-2665. doi:10.1007/s11661-007-9204-8

21. Song B, Syn C, Grupido C, Chen W, Lu W (2008) A long split Hopkinson pressure bar for intermediate rate characterization of soft materials. Exp Mech 48(6):809-815. doi:10.1007/s11340007-9095-Z

22. Chen W, Zhang B, Forrestal M (1999) A split Hopkinson bar technique for low-impedance materials. Exp Mech 39(2):81-85. doi:10.1007/BF02331109

23. Chen W, Lu F, Zhou B (1999) A quartz-crystal-embedded split Hopkinson pressure bar for soft materials. Exp Mech 40(1):1-6. doi:10.1007/BF02327540

24. Johnson T, Sarva S, Socrate S (2010) Comparison of low impedance split Hopkinson pressure bar techniques in the characterization of polyurea. Exp Mech 50(7):931-940. doi:10.1007/ s11340-009-9305-y

25. Cheng M, Chen W, Weerasooriya T (2005) Mechanical properties of Kevlar KM2 single fiber. J Eng Mater Technol 127(2):197-203. doi:10.1115/1.1857937

26. Lim J, Zheng J, Masters K, Chen W (2010) Mechanical behavior of A265 single fibers. J Mater Sci 45(3):652-661. doi:10.1007/ s10853-009-3979-5

27. Sanborn B, Weerasooriya T Effect of strain rates and pre-twist on tensile strength of Kevlar KM2 single fiber. ARL-TR-6403 2013

28. Crane NK Sierra/Solid Mechanics 4.22 User's Guide. Sandia Report SAND2011-7597, Sandia National Laboratories, Albuquerque, NM, 2011

29. Moy P, Weerasooriya T, Hsieh A, Chen W (2003) Strain rate response of a polycarbonate under uniaxial compression. Proceedings of the society of experimental mechanics international conference and exposition on experimental and applied mechanics

30. Bornert M, Bremand F, Doumalin P, Dupre J-C, Fazzini M, Grediac M, Hild F, Mistou S, Molimard J, Orteu J-J, Robert L, Surrel Y, Vacher P, Wattrisse B (2009) Assessment of digital image correlation measurement errors: methodology and results. Exp Mech 49:353-370. doi:10.1007/s11340-008-9204-7 